\title{
Efectos de probióticos y ácidos orgánicos sobre parámetros de incubación y producción en gallinas reproductoras
}

\author{
Michel, M.A.; Revidatti, F.A.; Fernández, R.J.; Sindik, M.L.; Sanz, S.P. \\ Cátedra Producción de Aves. Facultad de Ciencias Veterinarias, UNNE, \\ Cabral 2139, Corrientes 3400 (Argentina).E-mail: granja@vet.unne.edu.ar
}

\begin{abstract}
Resumen
Michel, M.A.; Revidatti, F.A.; Fernández, R.J.; Sindik, M.L.; Sanz, S.P.: Efectos de probióticos y ácidos orgánicos sobre parámetros de incubación y producción en gallinas reproductoras. Rev. Vet. 30: 2, $X X-X X, 2019$. Se estudiaron las respuestas correlacionadas entre los parámetros de la incubación en gallinas reproductoras pesadas suplementadas con una combinación de ácidos orgánicos y probióticos. Tres ensayos consecutivos fueron ejecutados durante los años 2013, 2014 y 2015. En cada ensayo, los reproductores fueron divididos en dos grupos: control y tratado, recibiendo agua y ácidos orgánicos con probióticos en agua de bebida durante 10 semanas consecutivas, respectivamente. En el grupo tratado se demostraron correlaciones negativas entre peso corporal a la semana 35 de la reproductora y peso del pollito $b b(\mathrm{r}=-0,99 ; \mathrm{p}=0,01)$; peso corporal promedio de la reproductora y total de huevos/gallina alojada $(\mathrm{r}=-0,97$; $\mathrm{p}=0,03)$; peso corporal promedio de la reproductora y producción de huevos $(r=-0,96$; $p=0,03)$; porcentaje de huevos incubables y porcentaje de huevos doble yema $(r=-0,96$; $\mathrm{p}=0,04)$. El grupo control mostró correlaciones negativas entre el peso corporal promedio de la reproductora y el porcentaje de huevos incubables $(r=-0,99 ; \mathrm{p}=0,01)$, y también entre el pico de producción de huevos y el peso del pollito de un día ( $\mathrm{r}=-0,99 ; \mathrm{p}=$ $0,04)$. Se registraron correlaciones positivas entre la uniformidad del peso corporal de la semana 35 y el peso del pollito de un día ( $\mathrm{r}=0,99 ; \mathrm{p}=0,05)$, así como la uniformidad de peso corporal y el peso promedio de los huevos $(\mathrm{r}=0,99 ; \mathrm{p}=0,03)$ en el grupo tratado. En el grupo control hubo una correlación positiva entre pico de producción de huevos y porcentaje de huevos rotos $(r=0,99 ; p=0,01)$. Existieron correlaciones entre las variables productivas y de incubabilidad que expresaron diferencias a favor de las aves tratadas con ácidos orgánicos y probióticos.
\end{abstract}

Palabras clave: gallinas ponedoras, probióticos, ácidos orgánicos, parámetros de incubación, producción.

Recibido: marzo 2019 / Aceptado: junio 2019

\begin{abstract}
Michel, M.A.; Revidatti, F.A.; Fernández, R.J.; Sindik, M.L.; Sanz, S.P.: Effects of probiotics and organic acids on incubation and production parameters in broilers. Rev. Vet. 30: 2, $X X-X X, 2019$. The effects of supplementing a blend of organic acids (OA) and a lactic acid bacteria based-probiotic on hatchery parameter correlated responses, were studied. Three independent trials were performed during 2013, 2014 and 2015. In each trial, broilers were divided into two groups: control and treated group, receiving regular water and $\mathrm{OA}$ with probiotic in the drinking water during 10 consecutive weeks, respectively. Treated group showed negative correlations between 35-weekold broiler body weight and chick body weight $(r=-0.99 ; \mathrm{p}=0.01)$; body weight and
\end{abstract}


total eggs per hen $(\mathrm{r}=-0.97 ; \mathrm{p}=0.03$ body weight and total egg production $(\mathrm{r}=-0.96 ; \mathrm{p}=$ $0.03)$; incubatable egg percentage and double yolk egg percentage $(r=-0.96 ; p=0.04)$. Control group showed negative correlations between broiler body weight and incubatable egg percentage $(r=-0.99 ; \mathrm{p}=0.01)$, as well as peak egg production and chick body weight $(\mathrm{r}=-0.99 ; \mathrm{p}=0.04)$. A positive correlation was found between 35-week-broiler body weight and chick body weight $(\mathrm{r}=0.99 ; \mathrm{p}=0.05)$, as well as body weight uniformity and eggs weight $(r=0.99 ; \mathrm{p}=0.03)$ in treated group. In control group there was a positive correlation between peak production and broken egg percentage $(r=0.99 ; p=0.01)$. There are correlations between productive and hatchery variables that show differences for treated group of broilers.

Key words: broiler breeders, probiotics, organic acids, incubation parameters, production.

\section{INTRODUCCIÓN}

La producción comercial de aves depende de la disponibilidad de pollitos $b b$ de un día. Por lo tanto, la fertilidad y la incubabilidad son dos parámetros primordiales correlacionados con el suministro de este recurso. Existen diversos factores que afectan la incubabilidad tales como la línea genética, el estado de salud y nutrición de los reproductores, la edad del lote, la calidad del huevo, así como las condiciones y la duración del almacenamiento del huevo ${ }^{18,36}$.

Sin embargo, los parámetros de calidad que más afectan la incubabilidad son: el peso del huevo, así como el espesor y la porosidad del cascarón ${ }^{6,44}$. Ya en 1982 se habían realizado investigaciones que demostraban la variación en el peso del pollito al nacer y mencionaban que se debía a la pérdida de peso del huevo durante la incubación y que las variaciones del peso del pollito derivaban, en gran medida, de la pérdida de agua durante la incubación 42 .

En las incubadoras comerciales, los huevos pierden peso debido a la evaporación de agua por difusión a través de la cáscara, por lo tanto dicha merma está determinada por la geometría del poro del caparazón (la conductancia del gas en la cáscara) y la humedad en el aire alrededor del huevo ${ }^{12,30}$.

La edad, la nutrición y el estado de salud de las reproductoras tienen una correlación directa con la calidad de los huevos, afectando su incubabilidad y la aptitud del pollito recién nacido ${ }^{28}$. La uniformidad en el lote de reproductores desde el fotoestímulo hasta el pico de producción es de vital importancia, guardando una estrecha relación con la nutrición y otros aspectos de manejo ${ }^{47}$.

El ajuste de los programas de alimentación aplicados durante este período ayudará a controlar el peso corporal, el peso del huevo y las patologías asociadas con la producción, como prolapsos, hígado graso o insuficiencia cardíaca, entre otros ${ }^{31}$.

En una publicación previa hemos reportado que la suplementación de reproductores pesados con ácidos orgánicos y probióticos basados en bacterias ácido-lácticas reducen la cantidad de huevos deformes y la mortalidad acumulada del lote, incrementando además la cantidad de pollitos obtenidos (Nutrition and Food Technologic Open Access, 2017, vol 3). El presente trabajo es la continuación de esos ensayos haciendo foco en la evaluación de las correlaciones encontradas entre parámetros de producción y de incubabilidad. 


\section{MATERIAL Y MÉTODOS}

Instalaciones. El trabajo se llevó a cabo en el paraje Los Lapachos (Provincia de Santa Fe, Argentina), en un galpón perteneciente a un complejo de reproductoras pesadas de la Unión Agrícola de Avellaneda). El predio de dicho complejo abarca una superficie de 488 hectáreas.

El galpón en donde se llevaron a cabo los estudios tenía una longitud de $140 \mathrm{~m}$ de largo por $14 \mathrm{~m}$ de ancho. Estaba dividido en sentido longitudinal en 2 compartimentos de iguales dimensiones que alojaban la misma cantidad de animales; la división imposibilitó que las aves pudieran cruzarse entre ambos sectores. La altura máxima fue de $4 \mathrm{~m}$ a nivel de la cumbrera y 2,5 m en los laterales. Contaba con ventilación de túnel con 12 extractores por galpón de 1,5 HP de potencia, contando además con sistema de aspersión y paneles evaporativos. En los laterales poseía cortinas azules con malacate.

Como implementos y accesorios existían 2 líneas de agua, con bebedero niple; los mismos eran circuitos independientes para cada mitad del galpón, estando conectados a tanques individuales de 500 litros cada uno, para realizar la administración de los tratamientos en forma separada. Existían circuitos de comederos automáticos para hembras con platos y sistema de alimentación manual con canaletas para los machos.

En el centro del galpón y en sentido longitudinal al mismo se encontraban los nidales (51 por sector) los cuales eran de recolección automática, realizándose la recogida de los huevos a través de una cinta transportadora hacia uno de los extremos del galpón. La misma presentaba una división al centro, para separar e identificar los huevos de cada sector.

La iluminación se realizó con focos de luz blanca halógena a una intensidad de 50 lux mínimo. El programa de iluminación comenzó con 12 h diarias a la fecha del alojamiento y se incrementó en función del porcentaje de postura diaria registrado, alcanzando un máximo de 16 h. Todo el equipamiento era automatizado y controlado por un software de la empresa Agrologic, programado según las necesidades. En la entrada a los nidales y correspondiendo al sector de las líneas de agua, existían slats plásticos, de 1,2 m de ancho; el resto del galpón tenía piso de cemento cubierto con cáscara de arroz.

Animales, manejo. Se trabajó con reproductores machos y hembras pertenecientes al híbrido comercial Cobb 500; fueron en promedio 9.000 hembras y 1.000 machos (incluyendo la reposición) por lote. Los ciclos de crianza se realizaron en cuatro años consecutivos (2012-2015) comprendiendo siempre el período de cría y recría (levante) entre los meses de marzo a julio (otoño-invierno), mientras que el alojamiento en el galpón de producción se realizó en el mes de agosto de cada año, registrándose las variables estudiadas en las siguientes 10 semanas (primavera).

La etapa de levante se llevó a cabo desde la primera semana de vida hasta las 22 semanas, en galpones blackout; luego se trasladó a los animales al galpón de producción donde fueron divididos al azar quedando la mitad de las aves en cada sector; una vez allí permanecieron en producción hasta la semana 64 de vida. En cada año, tanto el inicio a la postura como el patrón de evolución de la producción fueron normales para ambos grupos, conforme a los estándares de crianza descriptos por Cobb Argentina S.A. para ese híbrido comercial.

Alimentación. Se utilizaron 2 dietas para cada etapa del ciclo de producción, formuladas con materias primas convencionales (maíz y soja) y ajustadas a la demanda de 
las aves según su edad: pre-postura (18-24 semanas) y postura (26-64 semanas) tanto para machos como para hembras.

Diseño experimental. Cada ensayo duró 10 semanas consecutivas, desde la semana 25 a la 34 de vida de las aves. En cada ensayo, las aves fueron divididos en dos grupos de 5.000 animales (4.500 hembras y 500 machos en cada grupo). El grupo control recibió agua sin tratar, mientras que el grupo tratado recibió ácidos orgánicos en agua a una concentración de 4:1.000 litros de agua (vol/vol) según las instrucciones del fabricante. Veinticuatro horas después de la administración de los ácidos orgánicos, un probiótico a base de bacterias ácido lácticas fue administrado en el agua de bebida siguiendo las instrucciones del fabricante.

Cultivo probiótico. FloraMax ${ }^{\circledR}$ B11 (PacificVetGroup USA Inc., Fayetteville, AR 72703, USA) es un cultivo definido de probióticos aislados del tracto gastrointestinal de los pollos, consistiendo en 2 cepas de bacterias ácido lácticas: Lactobacillus salivarius y Pediococcus parvulus, que fueron seleccionadas basadas en sus habilidades in vitro para inhibir enteropatógenos ${ }^{26}$. La identifiación microbiológica fue confirmada por análisis de la secuencia 16S del ARN (Microbial ID Inc., Newark, DE 19713, USA). Este producto fue administrado acorde a las instrucciones del fabricante; la concentración final administrada una vez restituido en el agua de bebida fue de $10^{6} \mathrm{ufc} / \mathrm{ml}$.

Ácidos orgánicos. Un preparado comercial (Optimizer ${ }^{\circledR}$, PacificVetGroup-USA, Inc., Fayetteville, AR, 72703, USA) fue utilizado en el agua de bebida acorde a las instrucciones del fabricante (4 litros Optimizer ${ }^{\circledR} / 1.000$ litros agua). Este producto es una combinación de 5 diferentes ácidos (láctico, acético, tánico, propiónico y caprílico), conteniendo agentes flavorizantes.

Análisis estadístico. Se realizó estadística paramétrica descriptiva para cada una de las variables dependientes ordenadas según tratamientos. La distribución de todas ellas se constató mediante el método de Wilk-Shapiro modificado. Todas las pruebas fueron realizadas a través del paquete estadístico InfoStat ${ }^{\circledR}{ }^{13}$. Se aplicó análisis de la varianza (ANOVA) para un diseño en bloques completamente al azar (DBCA), evaluando las diferencias entre tratamientos de las variables dependientes y las relaciones entre ellas (correlación de Pearson), considerando límite un nivel de significancia del $5 \%{ }^{29,39}$.

\section{RESULTADOS Y DISCUSIÓN}

Los resultados productivos y reproductivos de los reproductores pesados evaluados con y sin la suplementación de una combinación de ácidos orgánicos y prebióticos, fueron publicados en un trabajo previo (Nutrition and Food Technologic Open Access, 2017, vol 3). En la Tabla 1 se muestra un resumen de las principales correlaciones halladas entre tales variables.

En todos los ensayos, la suplementación con ácidos orgánicos y probióticos durante 10 semanas consecutivas disminuyó significativamente $(\mathrm{p}<0,05)$ la pérdida de peso huevo-pollito (\%) comparado con el grupo control no tratado.

De manera similar, la suplementación con ácidos orgánicos y probióticos ácidoláctico mostró correlaciones negativas tales como: peso corporal a la semana 35 de la 
reproductora y peso del pollito $b b$; peso corporal promedio de la reproductora y total de huevos/gallina alojada; peso corporal promedio de la reproductora y producción de huevos; porcentaje de huevos incubables y porcentaje de huevos doble yema, cuando se los compara con el grupo control no tratado, como indica la Tabla 1.

Tabla 1. Correlación entre parámetros de producción evaluados con y sin la suplementación de ácidos orgánicos (AO) y probiótico (PB) en reproductores pesados.

\begin{tabular}{lccccc}
\hline \multicolumn{1}{c}{ variable } & variable & \multicolumn{2}{c}{ control } & \multicolumn{2}{c}{ AO + PB } \\
\cline { 3 - 6 } \multicolumn{1}{c}{} & 2 & $\mathrm{r}$ & $\mathrm{p}$-value & $\mathrm{r}$ & $\mathrm{p}$-value \\
\hline PC (semana 35) & peso pollito $b b$ & $-0,83$ & 0,38 & $-0,99^{*}$ & 0,01 \\
PC (promedio) & huevo por GA & $-0,72$ & 0,28 & $-0,97^{*}$ & 0,03 \\
PC (promedio) & producción de huevos & $-0,72$ & 0,28 & $-0,96^{*}$ & 0,03 \\
PC (promedio) & huevos incubables & $-0,99 *$ & 0,01 & $-0,58$ & 0,42 \\
uniformidad PC (semana 35) & peso pollito $b b$ & $-0,83$ & 0,38 & $0,99 *$ & 0,05 \\
uniformidad PC (promedio) & peso del huevo & $-0,99$ & 0,11 & $0,99 *$ & 0,03 \\
pico de producción de huevos & peso pollito $b b$ & $-0,99 *$ & 0,04 & $-0,99$ & 0,06 \\
pico de producción de huevos & huevos rotos & $0,99 *$ & 0,01 & 0,70 & 0,30 \\
huevos incubables & huevos doble yema & $-0,80$ & 0,19 & $-0,96 *$ & 0,04 \\
\hline
\end{tabular}

r: coeficiente de correlación; p-value: valor de probabilidad; PC: peso corporal; GA: gallina alojada. *valores de medias con correlaciones significativas $(\mathrm{p}<0,05)$. El tratamiento fue aplicado semanalmente por agua de bebida ( $\mathrm{AO}=4: 1$ litros; $\mathrm{PB}=10^{6} \mathrm{cfu}$-unidad formadora de colonia/ml). Los datos fueron registrados durante 10 semanas consecutivas (semanas $25^{\circ}$ a $35^{\circ}$ ) y el ensayo se repitió 3 veces en un DBCA.

Otros autores han relacionado el mayor peso corporal del ave con una mayor demanda metabólica de mantenimiento de los tejidos musculares y grasos de la reproductora, haciendo que la asignación de nutrientes de la dieta sea desviada a esta ruta metabólica en lugar de destinarse a la producción de huevos ${ }^{21}$.

Estudios previos demuestran que el manejo de la alimentación de los reproductores pesados en términos de cantidades y modalidad de distribución es fundamental, dada la amplia brecha entre el potencial genético para un alto peso corporal y el ideal para un correcto desempeño reproductivo, lo que hace necesario utilizar prácticas de restricción alimenticia que pueden disminuir la uniformidad de los pesos corporales de los lotes, y por consecuencia, un incorrecto manejo de la alimentación ${ }^{47}$.

Sin embargo, el grupo control mostró correlaciones negativas entre el peso corporal promedio de la reproductora y el porcentaje de huevos incubables, y también entre el pico de producción de huevos y el peso del pollito de un día cuando se los compara con el grupo tratado.

Por otro lado, se observaron correlaciones positivas entre la uniformidad del peso corporal de la semana 35 y el peso del pollito de un día, así como la uniformidad de peso corporal y el peso promedio de los huevos en las reproductoras suplementadas con ácidos orgánicos y probióticos (Tabla 1). En este sentido, la uniformidad de peso corporal más alta hace que el ajuste de la dieta a las necesidades de los animales sea más eficiente y se puedan asignar los nutrientes necesarios de manera más adecuada ${ }^{10}$.

Adicionalmente, en el grupo control hubo una correlación positiva entre pico de producción de huevos y porcentaje de huevos rotos (Tabla 1); un hallazgo similar fue reportado por otro autor, que describe que a mayores valores de uniformidad de peso 
corporal la producción es más alta, aunque paradójicamente también es mayor la proporción de huevos clasificados como rotos. La explicación posible propuesta por el autor aclara que la mayor demanda biológica en producción puede hacer que el animal necesite mayor cantidad de nutrientes, especialmente calcio, y como su asignación es limitada se ve comprometida la calidad de la cáscara ${ }^{1}$.

El peso corporal de los pollos al día de nacimiento está predominantemente determinado por el peso inicial del huevo incubado, representando entre un $62-78 \%$ del peso de dicho huevo ${ }^{7}$. Sin embargo, el peso del pollito de un día es también influenciado por la pérdida de peso del huevo durante el proceso de incubación, el peso de la cáscara, la línea genética y el tiempo de incubación, así como también la edad de las reproductoras y el sexo de los pollitos ${ }^{28,30}$.

Se ha estimado que $1 \mathrm{~g}$ de variación en el peso del huevo resulta en un cambio equivalente de 2 a $13 \mathrm{~g}$ del peso de un pollo a la edad de faena (6-8 semanas), y que este efecto está altamente correlacionado a la edad de la reproductora ${ }^{44}$.

Por otro lado, la intensa selección genética de los pollos parrilleros, que incluyen incremento de la tasa de crecimiento, rendimiento de carne de pechuga y reducción de la conversión alimenticia, se ha transformado en una espada de doble filo debido a que estos criterios de selección tienen también correlaciones negativas sobre el desempeño productivo de los reproductores, debido a que comprometen la aptitud reproductiva ${ }^{27}$.

Por lo dicho, programas estrictos de restricción alimenticia han sido implementados en reproductores pesados para limitar la ganancia de peso, evitar enfermedades y mantener altos parámetros de fertilidad ${ }^{47,48}$. Desafortunadamente, estos programas de restricción alimenticia no solo impactan en el bienestar de los animales, sino que también limitan la disponibilidad de nutrientes, aumentan el estrés y la permeabilidad intestinal, además de favorecer las disbacteriosis $19,20,22,43$.

Para minimizar estos efectos negativos sobre los reproductores, varios investigadores han reportado que la adición en las dietas de nutracéuticos tales como los prebióticos, probióticos, aceites esenciales y ácidos orgánicos, pueden incrementar el peso de la cáscara y su dureza, por ejercer un efecto mejorador de la disponibilidad de los nutrientes de las fórmulas y aumentar su absorción intestinal ${ }^{3,4,9,11,17,18,46}$.

Otros reportes científicos también han revelado que la inclusión dietaria de probióticos incrementa la calidad de la cáscara, la producción de huevos, el peso y masa de huevos y la dureza de la cáscara. La utilización de probióticos también ha mostrado una mejoría en el balance de la microflora intestinal, demostrando claramente la importancia de mantener la integridad del tracto gastrointestinal mediante una manipulación positiva del microbioma de los intestinos $2,38,40,45$.

Los resultados obtenidos en el presente estudio están en concordancia con una extensa cantidad de reportes que describen los beneficios de probióticos y ácidos orgánicos en la reducción de la pérdida de peso huevo/pollito y modificación de otros parámetros productivos relacionados al peso corporal, la uniformidad, la cantidad de huevos por gallina alojada y el porcentaje de huevos incubables descriptos en la Tabla 1, cuando se los compara con controles no tratados.

Resulta interesante observar que en el grupo no tratado, el peso corporal incrementó y hubo una significativa reducción de la cantidad de huevos incubables. Ello pudo deberse a la relación mencionada por otros autores entre el mantenimiento de un elevado peso corporal y la baja producción de huevos en las reproductoras pesadas ${ }^{34}$ y a que bajos requerimientos de mantenimiento posibilitan una mayor proporción de nutrientes 
disponibles para reproducción, correlacionando la eficiencia energética de mantenimiento con el total de huevos y pollitos obtenidos, así como su peso ${ }^{35}$.

De manera similar, correlaciones negativas y positivas fueron observadas para el pico de producción de huevos con el peso del pollito de un día, y pico de producción de huevos con cantidad de huevos rotos respectivamente en el grupo control (Tabla 1). Por el contrario, el grupo tratado no mostró tal correlación, lo cual parecería indicar que en estos animales el tratamiento favoreció una mejor asimilación y partición de los nutrientes de la dieta, que posibilitó poder alcanzar altos índices de producción de huevos, sin que el peso del pollito se viera perjudicado.

Se menciona que las principales modificaciones de la composición corporal que las reproductoras pesadas han recibido en los últimos años, logradas por selección genética, se pueden observar en el mayor tamaño y peso de la pechuga, pero al mismo tiempo en una menor cantidad de grasa corporal al momento de comenzar la postura, por lo que el animal depende en gran medida de su consumo diario para cubrir las demandas de crecimiento y reproducción ${ }^{14}$.

Alternativamente, la manipulación de bacterias benéficas en el intestino ha sido reportada como mejoradora del metabolismo del animal hospedador en varios sentidos, incluyendo la capacidad absortiva, el metabolismo proteico y energético, la digestión de fibra y la maduración intestinal ${ }^{5,23,37}$. El mantenimiento de un balance en la microflora intestinal y la inmunoestimulación, son los principales efectos funcionales atribuidos al consumo de prebióticos ${ }^{8,32}$.

Algunos de los mecanismos asociados con la mejoría de la calidad de la cáscara mediante nutracéuticos, incluyen un incremento de las tasas de fermentación intestinal. Los ácidos grasos de cadena corta tienen un sorprendente efecto sobre la fisiología digestiva, tal como la reducción del pH intestinal, el incremento de la absorción de calcio y la angiogénesis, así como también la proliferación de las células del epitelio intestinal 15, 33, 41, 46 . Actualmente, los campos de la inmunología, la microbiología y la nutrición convergen de manera sorprendente.

Los componentes de la dieta tienen un profundo efecto sobre la composición de la microflora intestinal, que a su vez repercute en la fisiología de los reproductores al mejorar varias funciones metabólicas que complementan la fisiología de las aves. Los componentes nutricionales de la dieta son de una importancia crítica no solo porque cumplen con los requerimientos nutricionales de los reproductores, sino también con los de su microflora gastrointestinal ${ }^{16,24,25}$.

Los resultados del presente estudio permiten confirmar que la suplementación de ácidos orgánicos y un probiótico a base de bacterias ácido-lácticas durante 10 semanas consecutivas (desde la semana 25 a la 35), mejoran los parámetros de incubación en reproductores pesados comerciales.

\section{REFERENCIAS}

1. Abbas SA et al. 2010. Effect of body weight uniformity on the productivity of broiler breeder hens. Int J Poult Sci 9: 225-230.

2. Abdelqader A, Irshaid R, Alfataftah AR. 2013. Effects of dietary probiotic inclusion on performance, eggshell quality, cecal microflora composition, and tibia traits of laying hens in the late phase of production. Trop Anim Health 45: 1017-1024. 
3. Abdel WA. 2016. Effect of dietary supplementation of thymol, synbiotic and their combination on performance, egg quality and serum metabolic profile of Hy-Line Brown hens. British Poultry Sci 57: 114-122.

4. Ajuwon K. 2015. Toward a better understanding of mechanisms of probiotics and prebiotics action in poultry species. J Appl Poultry Res 25: 277-283.

5. Bäckhed F. 2011. Programming of host metabolism by the gut microbiota. Ann Nutrit \& Metab 58: 44-52.

6. Bennett CD. 1992. The influence of shell thickness on hatchability in commercial broiler breeder flocks. J Appl Poultry Res 1: 61-65.

7. Bergoug HC et al. 2013. Effect of pre-incubation and incubation conditions on hatchability, hatch time and hatch window, and effect of post-hatch handling on chick quality at placement. World's Poultry Sci J 69: 313-334.

8. Borchers AT, Selmi C, Meyers FJ, Keen CL, Gershwin ME. 2009. Probiotics and immunity. J Gastroent 44: 26-46.

9. Bozkurt M, Alçiçek A, Cabuk M, Küçükyilmaz K, Catli AU. 2009. Effect of an herbal essential oil mixture on growth, laying traits, and egg hatching characteristics of broiler breeders. Poult Sci 88: 2368-2374.

10. Carneiro PR. 2016. Effect of precision feeding on uniformity and efficiency of broiler breeder pullets. Doctoral dissertation, University of Alberta. https://era.library.ualberta.ca/items/206c1da7-14fc-44b2-91bb-a4dfe0112884

11. Chung SH, Lee J, Kong C. 2015. Effects of multi strain probiotics on egg production and quality in laying hens fed diets containing food waste product. Int J Poultry Sci 14: 19-22.

12. Deeming CD. 2011. A review of the relationship between eggshell colour and water vapour conductance. Avian Biol Res 4: 224-230.

13. Di Rienzo JA. 2008. InfoStat, FCA, Universidad Nacional de Córdoba, Argentina. https://scholar.google.com.ar/citations? user $=y u m G X j o A A A A J \& h l=e n$

14. Eitan Y, Lipkin E, Soller M. 2014. Body composition and reproductive performance at entry into lay of anno 1980 versus anno 2000 broiler breeder females under fast and slow release from feed restriction. Poultry Sci 93: 1227-1235.

15. Högberg A, Lindberg JE. 2004. Influence of cereal non-starch polysaccharides and enzyme supplementation on digestion site and gut environment in weaned piglets. Anim Feed Sci \& Technol 116: 113-128.

16. Howarth GS, Wang H. 2013. Role of endogenous microbiota, probiotics and their biological products in human health. Nutrients 5: 58-81.

17. Khan RU, Ziaur R, Javed I, Muhammad F. 2014. Serum antioxidants and trace minerals as influenced by vitamins, probiotics and proteins in broiler breeders. $J$ Applied Anim Res 42: 249-255.

18. King A. 2011. Review of the factors that influence egg fertility and hatchability in poultry. Int J Poultry Sci 10: 483-492.

19. Kuttappan VA et al. 2015a. Poultry enteric inflammation model with dextran sodium sulfate mediated chemical induction and feed restriction in broilers. Poultry Sci 94: 1220-1226.

20. Kuttappan VA et al. 2015b. Evaluation of gastrointestinal leakage in multiple enteric inflammation models in chickens. Front Vet Sci 2: 66.

21. Leksrisompong N, Romero SH, Oviedo EO, Brake J. 2014. Effect of feeder space during the growing and laying periods and the rate of feed increase at the onset of lay on broiler reproductive function. Poultry Sci 93: 1599-1607. 
22. Leone E, Estévez I. 2008. Economic and welfare benefits of environmental enrichment for broiler breeders. Poultry Sci 87: 14-21.

23. Liang X, Bushman FD, Fitzgerald GA. 2014. Time in motion: the molecular clock meets the microbiome. Cell 159: 469-470.

24. Lyte M. 2011. Probiotics function mechanistically as delivery vehicles for neuroactive compounds: microbial endocrinology in the design and use of probiotics. Bioessays 33: $574-581$.

25. Maslowski KM, Mackay CR. 2010. Diet, gut microbiota and immune responses. Nature Imm 12: 5-9.

26. Menconi A et al. 2014. Evaluation of a commercially available organic acid product on body weight loss, carcass yield, and meat quality during preslaughter feed withdrawal in broiler chickens. Poultry Sci 93: 448-455.

27. Peebles ED, Brake J. 1985. Relationship of eggshell porosity to stage of embryonic development in broiler breeders. Poultry Sci 64: 2388-2391.

28. Peebles ED, Brake J, Gildersleeve R. 1987. Effects of eggshell cuticle removal and incubation humidity on embryonic development and hatchability of broilers. Poultry Sci 66: 834-840.

29. Poole R. 1974. Sampling and the estimation of population parameters. An introduction to quantitative ecology, McGraw Hill, New York, p. 292-324.

30. Rahn H, Ar A. 1974. The avian egg: incubation time and water loss. Condor 76: 147-152.

31. Renema R, Robinson F, Zuidhof M. 2007. Reproductive efficiency and metabolism of female broiler breeders as affected by genotype, feed allocation, and age at photostimulation. 2. Sexual maturation. Poultry Sci 86: 2267-2277.

32. Revolledo L, Ferreira A, Mead G. 2006. Prospects in salmonella control: competitive exclusion, probiotics, and enhancement of avian intestinal immunity. J Appl Poultry Res 15: 341-351.

33. Ricke S. 2003. Perspectives on the use of organic acids and short chain fatty acids as antimicrobials. Poultry Sci 82: 632-639.

34. Robinson FE, Wilson JL, Yu MW, Fasenko GM, Hardin RT. 1993. The relationship between body weight and reproductive efficiency in meat-type chickens. Poultry Sci 72: 912-922.

35. Romero LF, Zuidhof M, Renema R, Naeima A, Robinson F. 2009. Characterization of energetic efficiency in adult broiler breeder hens. Poultry Sci 88: 227-235.

36. Roque L, Soares M. 1994. Effects of eggshell quality and broiler breeder age on hatchability. Poultry Sci 73: 1838-1845.

37. Shen J, Obin MS, Zhao L. 2013. The gut microbiota, obesity and insulin resistance. Molec Aspects Med 34: 39-58.

38. Sobczak A, Kozlowski K. 2015. The effect of a probiotic preparation containing Bacillus subtilis ATCC PTA-6737 on egg production and physiological parameters of laying hens. Annals Anim Sci 15: 711-723.

39. Steel R, Torrie J. 1988. Bioestadística: principios y procedimientos, McGrawHill/Interamericana, México, 622 p.

40. Sultan KH, Abdul R. 2011. Effect of probiotic on some physiological parameters in broiler breeders. Int J Poultry Sci 10: 626-628.

41. Tellez G, Higgins S, Donoghue A, Hargis B. 2006. Digestive physiology and the role of microorganisms. J Appl Poultry Res 15: 136-144. 
42. Tullett SG, Burton FG. 1982. Factors affecting the weight and water status of the chick at hatch. British Poultry Sci 23: 361-369.

43. Vicuña $\mathbf{E}$ et al. 2015. Effect of dexamethasone in feed on intestinal permeability, differential white blood cell counts, and immune organs in broiler chicks. Poultry Sci 94: 2075-2080

44. Wilson H. 1991. Interrelationships of egg size, chick size, posthatching growth and hatchability. World's Poultry Sci J 47: 5-20.

45. Xu CL et al. 2006. Effects of a dried Bacillus subtilis culture on egg quality. Poultry Sci 85: 364-368.

46. Youssef AW, Hassan H, Ali H, Mohamed M. 2013. Effect of probiotics, prebiotics and organic acids on layer performance and egg quality. Asian J Poult Sci 7: 110.

47. Zuidhof $\mathbf{M}$ et al. 2015. Effects of broiler breeder management on pullet body weight and carcass uniformity. Poultry Sci 94: 1389-1397.

48. Zulkifli I et al. 1993. Responses of dwarf and normal chickens to feed restriction, Eimeria tenella infection, and sheep red blood cell antigen. Poultry Sci 72:16301640. 